\title{
Craniometaphyseal dysplasia (CMD), autosomal dominant form
}

\author{
P Beighton
}

The autosomal dominant form of craniometaphyseal dysplasia (CMD) (MIM 123000) is a well defined disorder in which mild to moderate overgrowth of the craniofacial bones leads to asymmetry of the mandible, cranial nerve compression, variable hearing loss, and facial palsy. Between 50 to 100 affected persons have been documented, including several large multigeneration families.

The autosomal recessive form of CMD (MIM 218400) is a rare, severe condition in which marked bone overgrowth leads to distortion of the facies with blindness, deafness, and facial palsy. Fewer than 10 cases have been reported and syndromic boundaries are ill defined.

\section{Historical background}

In 1954 Peter Jackson, an English physician on the staff of Groote Schuur Hospital, University of Cape Town, took a fellowship in endocrinology with Fuller Albright at Massachusetts General Hospital, Boston. As part of a study of constitutional and metabolic skeletal

MRC Research Unit for Medical Genetics, Department of Human Genetics,

Medical School,

University of Cape

Town,

Observatory 7925,

South Africa

P Beighton

Figure 1 The proband, aged 39 years. He had bilateral perceptive deafness and facial weakness which had been present since childhood. A mandibular recession operation had been performed at the age of 18 years. disease, Jackson, Albright, and colleagues reviewed disorders of osseous modelling and identified a specific syndrome which comprised dysplasia of the metaphyses, sclerosis of the base of the skull, and overgrowth of the craniofacial bones. They culled five previously reported cases, added two of their own, and termed the condition "craniometaphyseal dysplasia". ${ }^{1}$ Of the five previously reported patients, three had been designated "osteopetrosis" and two "leontiasis ossea". (This archaic, non-specific descriptive term pertains to a "lion-like facies", which has many causes and it does not denote any particular disorder.)

Following the delineation of CMD, Mori and $\mathrm{Holt}^{2}$ documented three affected persons, using the title "familial metaphyseal dysplasia". One of these patients had three affected relatives, with generation to generation transmission. Subsequently, Spranger $e t a l^{\beta}$ reported a similar family, while other authors described sporadic cases or sets of sibs with a much more severe form of the condition, in which inheritance was apparently autosomal recessive. ${ }^{4-7}$ The nosological situation was clarified in 1969, when Gorlin et al, ${ }^{8}$ in their seminal review of the sclerosing bone dysplasias, clearly established the separate syndromic identity of the $A D$ and $A R$ forms of CMD. Since that time, there have been many reports of $\mathrm{CMD}$ and it has become evident

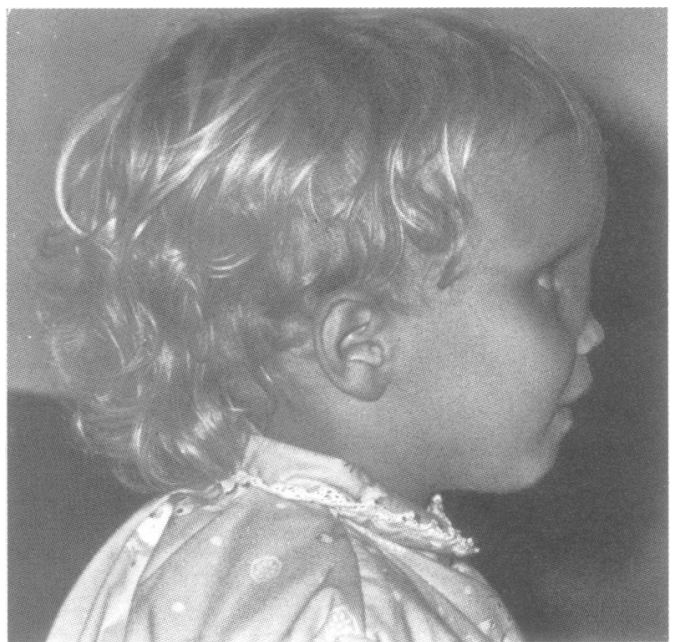

Figure 2 The daughter of the proband, aged 2 years. Gross paranasal bossing is evident. 


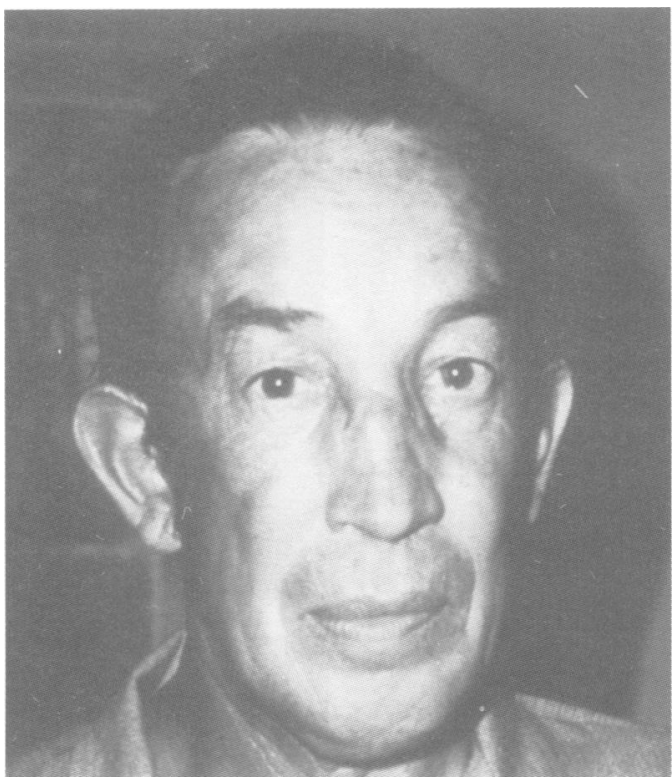

Figure 3 The brother of the proband aged 47 years. The mandible is prominent and somewhat asymmetrical. $A$ right sided facial palsy is present.

that the $\mathrm{AD}$ form is relatively mild and comparatively common, while the AR form is rare, severe, and possibly heterogeneous.

\section{Clinical features and natural history}

In the $\mathrm{AD}$ form of $\mathrm{CMD}$ affected persons usually enjoy good general health, stature is normal, intellect is unimpaired, and there are no systemic ramifications. The bones are not fragile and dyshaematopoiesis does not occur. The clinical manifestations are summarised below. In themselves they do not permit firm diagnosis, for which radiographic studies are necessary. ${ }^{910}$ The clinical and radiographic features of a family with $\mathrm{AD}$ CMD are depicted in figs 1 to 9 .

FACIAL DISTORTION

Progressive bone overgrowth in AD CMD can cause mild to moderate mandibular pro- gnathism and malalignment of the teeth. By contrast, distortion of the facies in AR CMD is very severe.

The AD form of CMD may present in infancy with bony paranasal bossing. This curious feature tends to regress with growth, and by adolescence or early adulthood it may be virtually absent. Some degree of nasal obstruction may be present and mouth breathing is frequent.

\section{CRANIAL NERVE COMPRESSION}

Bone overgrowth and sclerosis at the base of the skull leads to variable compression of the seventh and eighth cranial nerves. Unilateral or bilateral facial palsy may occur at any age; in early childhood, involvement is often fluctuant but by adulthood facial palsy may be permanent. This complication is common but variable and not all persons with AD CMD develop permanent facial palsy.

If the auditory nerve and inner ear are compromised by bone overgrowth, unilateral or bilateral deafness may develop. Involvement of the bony components of the middle ear and chronic otitis media and upper respiratory tract infection owing to minor anatomical abnormalities of the airway and sinuses may compound the hearing loss, which is often "mixed" in type. Fortunately, deafness, if present at all, is usually partial and rarely profound.

In AR CMD, cranial nerve compression is severe, and in addition to facial palsy and deafness, visual loss may result from involvement of the optic nerve. This latter complication does not occur in $\mathrm{AD} \mathrm{CMD}$.

\section{RAISED INTRACRANIAL PRESSURE}

Hyperostosis of the calvarium leads to a potentially lethal rise in intracranial pressure in several of the sclerosing bone dysplasias, notably sclerosteosis and AR CMD. As the calvarium is not significantly widened in $A D$ CMD, this complication is rare but not unprecedented. Indeed, an affected girl known to the author underwent craniectomy in late childhood for this complication.

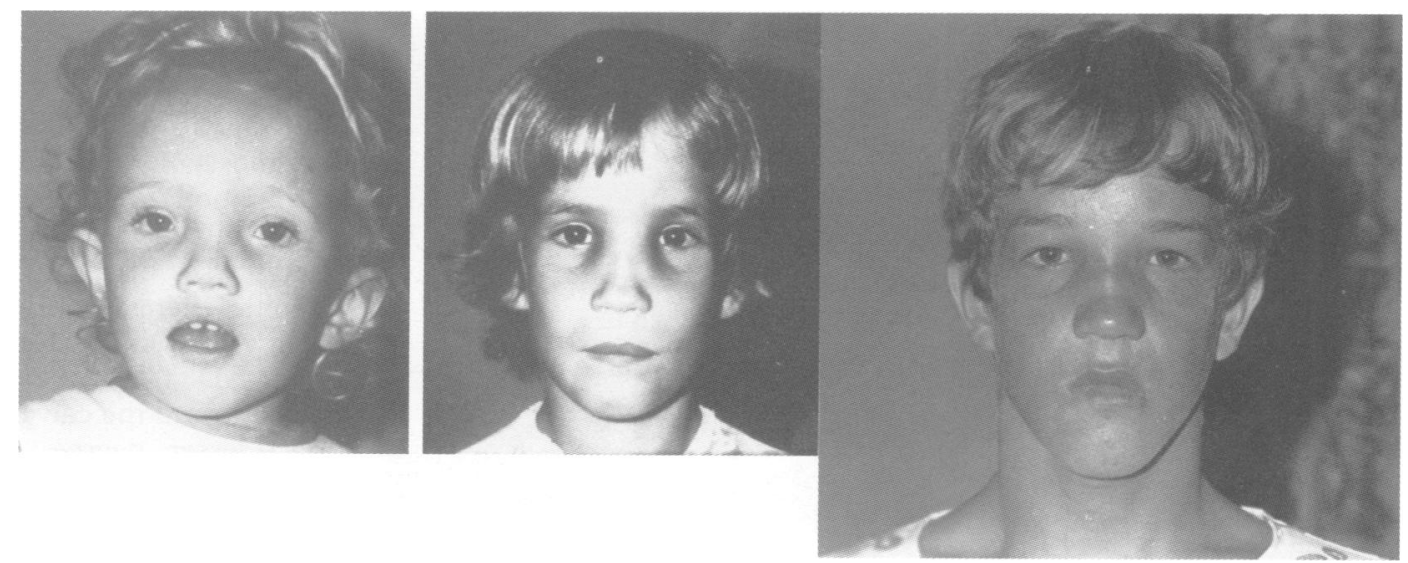

Figure 4 The affected children of the patient depicted in fig 3, from left to right at the respective ages of 3, 8, and 15 years. Paranasal bossing and age related mandibular overgrowth are evident. 


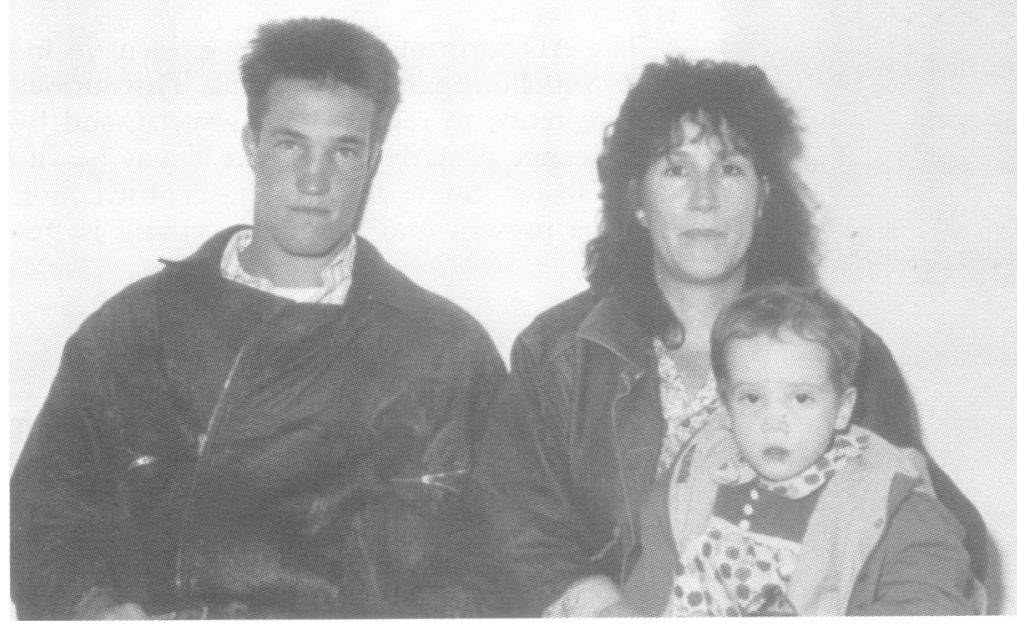

Figure 5 The proband's affected sister with her two affected children. Apart from mandibular prominence, their facies are not markedly abnormal but each had the characteristic radiological features.

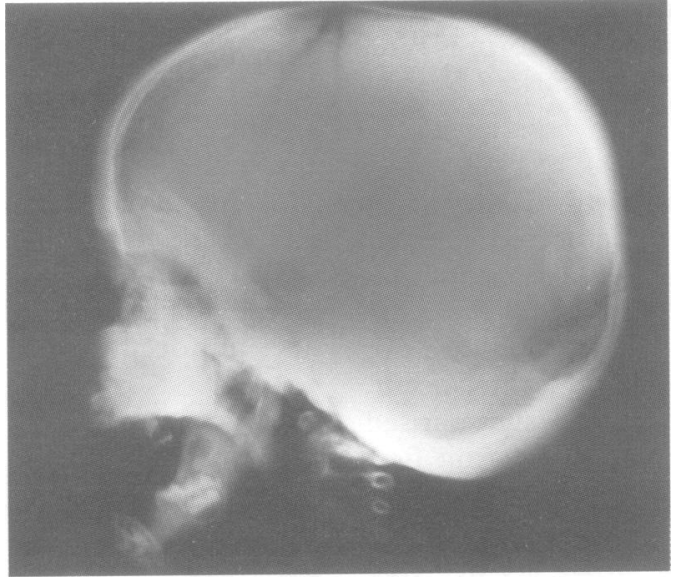

Figure 6 Lateral skull radiograph of the affected girl aged 3 years. The base of the skull is sclerotic, and the calvarium is similarly involved, to a lesser extent.

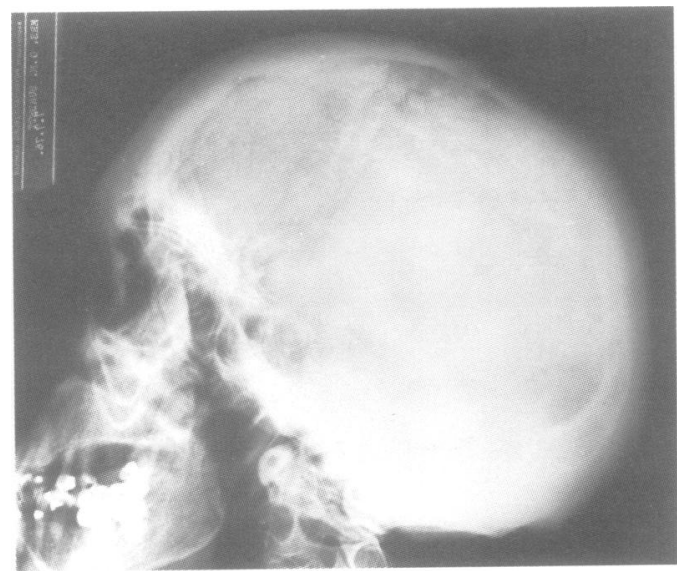

Figure 7 Lateral skull radiograph of the proband, aged 39 years. The base and calvarium are very sclerotic, without significant hyperostosis.

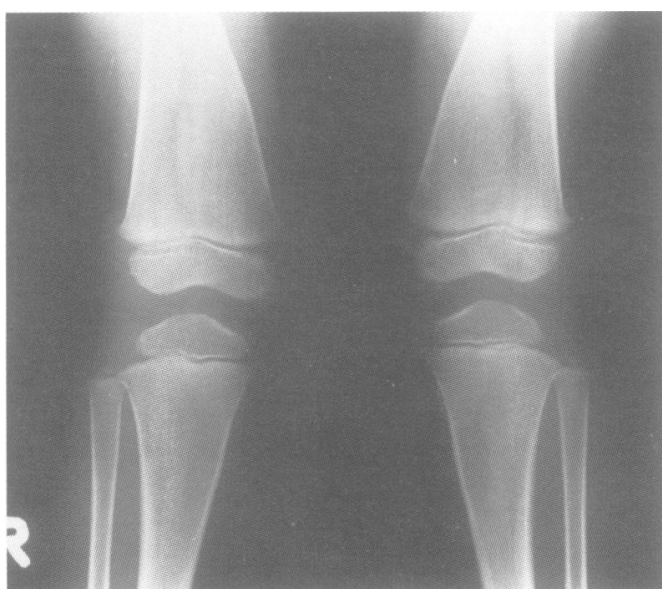

Figure 8 Anteroposterior radiograph of the knees of an affected girl, aged 7 years. Defective modelling of the lower femoral metaphyses has produced a "flask shaped" configuration.

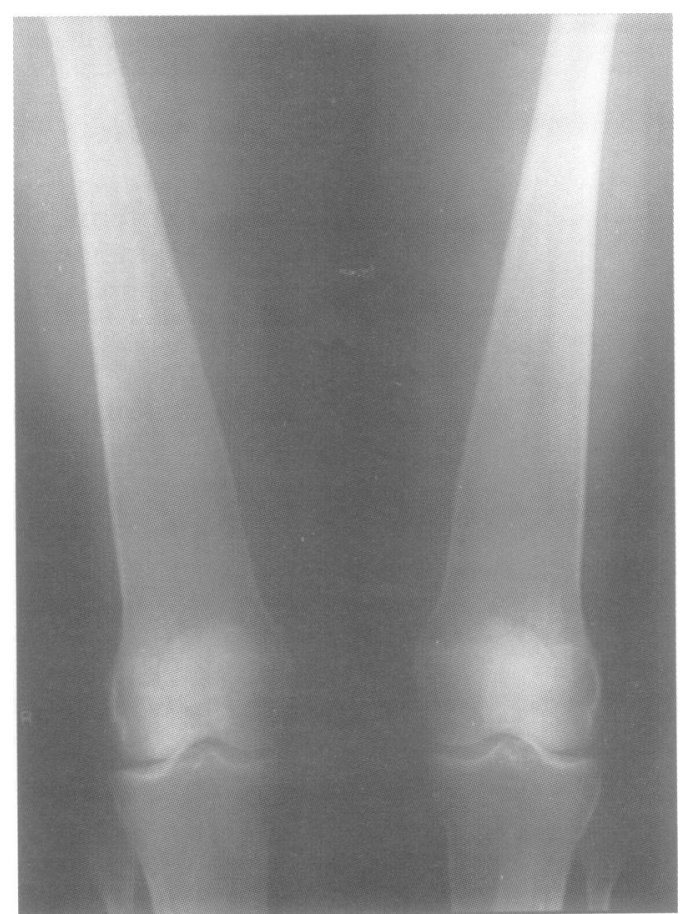

Figure 9 Anteroposterior radiograph of the knees of the proband's brother at the age of 47 years. The lower femoral metaphyses are "club shaped". In distinction to the skull, the long bones are not sclerotic; indeed, as shown in this radiograph, their cortices are thin.

\section{Radiographic features}

Diagnosis of AD CMD is dependent upon the recognition of the characteristic sclerosis of the skull and non-sclerotic widening of the metaphyses of the tubular bones. The radiographic changes, which are age related, have been reviewed by $\mathrm{Holt}^{9}$ and Spiro et al. ${ }^{10}$

In $\mathrm{AD} C M D$, the base of the skull is sclerotic and the calvarium is similarly affected to a lesser degree. In adulthood, sclerosis may be especially evident along the cranial sutures. The air sinuses may be obliterated and paranasal bony bossing, which is most evident in early childhood, may give a spurious appearance of hypertelorism. Man- 
Clinical and radiological features of the craniometaphyseal dysplasias and Pyle disease

\begin{tabular}{|c|c|c|c|}
\hline & $\begin{array}{l}C M D \\
A D \text { type }\end{array}$ & $\begin{array}{l}C M D \\
\text { AR type }\end{array}$ & $\begin{array}{l}\text { Pyle } \\
\text { disease }\end{array}$ \\
\hline $\begin{array}{l}\text { Reported cases } \\
\text { Clinical features }\end{array}$ & $50+$ & $10+$ & $20+$ \\
\hline Facial distortion & + & +++ & - \\
\hline Cranial nerve palsy & + & ++ & - \\
\hline Bone fragility & - & - & + \\
\hline Radiographic features & & & \\
\hline $\begin{array}{l}\text { Cranial sclerosis } \\
\text { Modelling defects in long bones } \\
\text { Configuration of distal femora }\end{array}$ & $\begin{array}{l}++ \\
+ \\
\text { Club shaped }\end{array}$ & $\begin{array}{l}+++ \\
\stackrel{+}{\text { Club shaped }}\end{array}$ & $\begin{array}{l}+ \\
++ \\
\text { Erlenmayer flask }\end{array}$ \\
\hline
\end{tabular}

dibular prognathism and asymmetry may also be present.

Widening of the metaphyses of the long bones is a major feature of CMD. These bones are not sclerotic, and in the affected regions the cortices are thin. These changes are most obvious at the lower end of the femur which has an "Erlenmeyer flask" configuration in childhood and a "club" shape in adulthood.

The spine and pelvis are normal and in the chest the only significant changes are very mild modelling defects of the medial portions of the clavicles and costochondral junctions.

In AR CMD the radiographic manifestations are severe, especially in the skull, which is sclerotic and hyperostotic. The metaphyses of the long bones are widened, but not sclerotic; the skeleton is otherwise essentially normal.

\section{Differential diagnosis}

CMD has been the source of considerable semantic confusion. In particular, the term "metaphyseal dysplasia" has been applied to Pyle disease, which is a distinctive AR condition with gross metaphyseal expansion, but lacking any significant cranial sclerosis ${ }^{112}$ (table). As previously mentioned, the non-specific descriptive term "leontiasis ossea" has been applied to persons with the severe AR CMD. In the same way, the term "osteopetrosis" or "Albers-Schönberg" disease has often been used in a non-specific sense for many sclerosing bone dysplasias, including CMD. ${ }^{13}$

Other conditions which bear some resemblance to $\mathrm{CMD}$ include craniodiaphyseal dysplasia (CDD), $\mathrm{AD}$ and $\mathrm{AR}$ forms, frontometaphyseal dysplasia, and sclerosteosis. These disorders can all be distinguished radiologically by the extent and anatomical distribution of the skeletal changes. ${ }^{14}$ The AR form of CMD must be distinguished from conditions in which overgrowth of the craniofacial skeleton is extreme; the AR type of CDD is the most common of these rare entities.

\section{Genetics}

Autosomal dominant transmission of CMD was present in a kindred reported by Komins, ${ }^{15}$ in which four affected persons in two generations were documented under the erroneous title "Familial metaphyseal dysplasia (Pyle disease)". A multigeneration family with CMD was also reported by Mori and $\mathrm{Holt}^{2}$ under the same misnomer. A father and daughter with the condition were described by Stool and Caruso, ${ }^{16}$ and in 1979 Beighton et $a l^{17}$ published an account of 15 affected persons in five generations of a South African family of British stock. Other reports concerned a Mexican family with typical AD CMD in three generations ${ }^{18}$ and an Australian kindred with nine affected persons in four generations. ${ }^{19} \mathrm{An}$ other large kindred with $\mathrm{AD}$ CMD was documented by Rimoin et $a l^{20}$ but the correct title "craniometaphyseal dysplasia" was marred by the addition of the erroneous eponymic term "Pyle disease".

In all the above mentioned families, the ratios of males to females and affected to unaffected persons were in general conformity with autosomal dominant inheritance; equally there were several instances of male to male transmission. ${ }^{21}$ There was no obvious sex influence on phenotypical expression, but some variation in severity was evident in several of the affected families. Indeed, in the Mexican family ${ }^{18}$ at least two persons were unaware that they were affected until the diagnosis was confirmed by radiological demonstration of metaphyseal widening.

The AR form of CMD is rare, ill defined, and probably heterogeneous, and often difficult to diagnose with precision. ${ }^{6}$ Nevertheless in the few reports concerning this disorder or group of disorders, there is good evidence for AR inheritance. Parental consanguinity has been mentioned $^{5}$ and sets of affected sibs have been noted. ${ }^{4622}$ Additional stigmata which may indicate further heterogeneity include wormian bones $^{23}$ and bone fragility. ${ }^{24}$ The syndromic significance of complications such as isolated accounts of hydrocephalus, ${ }^{25}$ cervical spine deformity, ${ }^{26}$ and mental retardation ${ }^{27}$ is uncertain.

There are several reports of sporadic patients with severe CMD; it is likely that many of them have the AR form, but in the absence of positive genealogical data, and in view of the phenotypical variability, it is difficult for this diagnosis to be clinched.

\section{Basic defect}

The nature of the basic defect in $\mathrm{AD} C M D$ is unknown. The cranial sclerosis and the abnormal modelling of the metaphyses have been attributed to the defective osteoclastic activity but at present this view is speculative. ${ }^{28}$

In AR CMD the metabolic responses of two affected children to therapy with calcitonin ${ }^{29}$ and calcitrol ${ }^{30}$ may indicate that the basic defect involves dysfunctional osteoclasts. This issue is clouded, however, by problems concerning 
possible heterogeneity and these observations must be interpreted with caution. The pathophysiology of CMD was investigated in an affected boy aged 3 years, possibly with AR CMD, by Yamamoto et al. ${ }^{31}$ Using specific monoclonal antibodies these workers showed that osteoclast-like cells derived from the bone marrow lacked expression of the osteoclast vacuolar proton pump.

A possible clue to the chromosomal location of the faulty gene in CMD is provided by the observation of an affected female child with a translocation between chromosomes 12 and 18 , with the regions $q 13 ; q 12$ being involved. ${ }^{26}$ As with many sporadic examples of CMD, however, it is uncertain which form of the disorder was implicated.

I am grateful to Mrs Gillian Shapley and Mrs Greta Beighton for typing the manuscript. This work was supported by grants from the Medical Research Council for South Africa, the Coope Lowveld Foundation, the Mauerberger Foundation, and the University of Cape Town Staff Research Fund. The illustration in this article are derived from Beighton $\mathrm{P}$, Hamersma $\mathrm{H}$, Horan F. Clin Genet 1979;15:252-258 and Beighton P, Cremin B.
Sclerosing bone dysplasias. Heidelberg: Springer. They are reSclerosing bone dysplasias. Heidelberg: Sp
produced with the publishers' permission.

1 Jackson WPU, Albright F, Drewery G, Hanelin J, Rubin MI Metaphyseal dysplasia, epiphyseal dysplasia, diaphysea dysplasia and related conditions. Arch Intern Med 1954 94/6:871-85.

2 Mori PA, Holt JF. Cranial manifestations of familial metaphyseal dysplasia. Radiology 1956;66:335-43.

3 Spranger J, Paulsen J, Lehmann W. Die kraniometaphysaer Dysplasie (Pyle) Z Kinderheilkd 1965;93:64-79.

4 Lehmann ECH. Familal osteodystrophy of the skull and face. F Bone foint Surg (Br) 1957;39:313-15.

5 Lievre JA, Fischgold DH. Leontiasis ossea chez l'enfan (osteopetrose partielle probable). Presse Med 1956;64:763

6 Millard DR, Maisels DD, Batsone JHF, Yates BW. Craniofacial surgery in craniometaphyseal dysplasia. Am f Surg 1967;113:615-21.

7 Ross MW, Altman DH. Familial metaphyseal dysplasia. Review of the clinical and radiologic features of Pyle's disease Clin Pediatr 1967;63:143-9.

8 Gorlin RJ, Spranger J, Koszalka MF. Genetic craniotubula bone dysplasias and hyperostoses. A critical analysis. Birth Defects $1969 ; 5(4): 79-95$.

9 Holt JF. The evolution of crani-metaphyseal dysplasia. Ann Radiol (Paris) 1966;9:209-14.

10 Spiro PC, Hamersma H, Beighton P. Radiology of the autosomal dominant form of craniometaphyseal dysplasia. $S$ Afr Med F 1975;49:839-42.

11 Heselson NG, Raad MS, Hamersma H, Cremin BJ, Beighton P. The radiological manifestations of metaphysed

12 Raad MS, Beighton P. Autosomal recessive inheritance of metaphyseal dysplasia (Pyle disease). Clin Genet 1978;14: 251-6.

13 Beighton P, Horan F, Hamersma $\mathrm{H}$. A review of the osteopetroses. Postgrad Med $\mathcal{F}$ 1977;53:507-16.

14 Greenspan A. Sclerosing bone dysplasias - a target-site approach. Skeletal Radiol 1991;20:561-83.

15 Komins C. Familial metaphyseal dysplasia (Pyle's disease) Br ₹ Radiol 1954;27:670-5.

16 Stool SE, Caruso VG. Cranial metaphyseal dysplasia. Arch Otolaryngol 1973;97:410.

17 Beighton P, Hamersma H, Horan F. Craniometaphyseal dysplasia - variability of expression within a large family. Clin Genet 1979;15:252-8.

18 Carnevale A, Grether P, del Castillo V, Takenaga R, Orzechowski A. Autosomal dominant craniometaphyseal dysplasia. Clinical variability. Clin Genet 1983;23:17-22.

19 Taylor DB, Sprague P. Dominant craniometaphyseal dysplasia - a family study over five generations. Australa Radiol 1989;33:84-9.

20 Rimoin DL, Woodruff SL, Holman BL. Craniometaphysea dysplasia (Pyle's disease): autosomal dominant inheritance in a large kindred. Birth Defects 1969;4:96-104.

21 Bricker SL, Langlais RP, van Dis ML. Dominant craniometaphyseal dysplasia. Literature review and case report. Dentomaxillofac Radiol 1983;12:95-100.

22 Penchaszadeh VB, Gutierrez ER, Figueroa E. Autosoma recessive craniometaphyseal dysplasia. Am $7 \mathrm{Med}$ Genet $1980 ; 5: 43-55$.

23 Langer LO Jr, Brill PW, Afshani E, Williams CA, Thomas IT, Frias JL. Radiographic features of craniometadiaphyseal dysplasia, wormian bone type. Skeletal Radiol 1991;20: dysplas.

24 Ventruto V, Ametrano O, D'Avanzo G, et al. A case of autosomal recessive form of craniometaphyseal dysplasia with unusual features and with bone fragility. Australas Radiol 1987;31:79-82.

25 Hudgin RI, Edwards MS. Craniometaphyseal dysplasia associated with hydrocephalus: case report. Neurosurgery associated with hy

26 Yamada $H$, Yamanaka $T$, Tanaka Y, Nakamura S. Cervica spinal deformity in craniometaphyseal dysplasia. Surg $\mathrm{Ne}$ spinal deformity in cra

27 Portnov VA, Marincheva GS, Gorbachevskaia NL. Familial craniometaphyseal dysplasia associated with mental recraniometaphyseal dysplasia associated with mental

28 Cole DE, Cohen MM Jr. A new look at craniometaphyseal dysplasia. F Pediatr 1988;112:577-9.

29 Fanconi S, Fischer JA, Wieland P, et al. Craniometaphysea dysplasia with increased bone turnover and secondary hyperparathyroidism: therapeutic effect of calcitonin. $f$ Pediatr 1988;112:587-91.

30 Key LL Jr, Volberg F, Baron R, Anast CS. Treatment of craniometaphyseal dysplasia with calcitriol. F Pediatr 1988 112:583-7.

31 Yamamoto T, Kurihara N, Yamaoka K, et al. Bone marrowderived osteoclast-like cells from a patient with craniometaphyseal dysplasia lack expression of osteoclast-reactive vacuolar proton pump. 7 Clin Invest 1993;91:362-7. 